\title{
Ozone mixing ratios inside tropical deep convective clouds from OMI satellite measurements
}

\author{
J. R. Ziemke ${ }^{1,2}$, J. Joiner ${ }^{2}$, S. Chandra ${ }^{1,2}$, P. K. Bhartia ${ }^{2}$, A. Vasilkov $^{3}$, D. P. Haffner ${ }^{3}$, K. Yang ${ }^{1,2}$, M. R. Schoeberl ${ }^{2}$, \\ L. Froidevaux ${ }^{4}$, and P. F. Levelt ${ }^{5}$ \\ ${ }^{1}$ Goddard Earth Sciences and Technology, University of Maryland Baltimore County, Baltimore, Maryland, USA \\ ${ }^{2}$ NASA Goddard Space Flight Center, Greenbelt, Maryland, USA \\ ${ }^{3}$ Science System and Applications, Inc., Lanham, Maryland, USA \\ ${ }^{4}$ NASA Jet Propulsion Laboratory, Pasadena, California, USA \\ ${ }^{5}$ Royal Dutch Meteorological Institute, KNMI, De Bilt, The Netherlands
}

Received: 26 June 2008 - Published in Atmos. Chem. Phys. Discuss.: 26 August 2008

Revised: 12 December 2008 - Accepted: 12 December 2008 - Published: 27 January 2009

\begin{abstract}
We have developed a new technique for estimating ozone mixing ratio inside deep convective clouds. The technique uses the concept of an optical centroid cloud pressure that is indicative of the photon path inside clouds. Radiative transfer calculations based on realistic cloud vertical structure as provided by CloudSat radar data show that because deep convective clouds are optically thin near the top, photons can penetrate significantly inside the cloud. This photon penetration coupled with in-cloud scattering produces optical centroid pressures that are hundreds of $\mathrm{hPa}$ inside the cloud. We combine measured column ozone and the optical centroid cloud pressure derived using the effects of rotational-Raman scattering to estimate $\mathrm{O}_{3}$ mixing ratio in the upper regions of deep convective clouds. The data are obtained from the Ozone Monitoring Instrument (OMI) onboard NASA's Aura satellite. Our results show that low $\mathrm{O}_{3}$ concentrations in these clouds are a common occurrence throughout much of the tropical Pacific. Ozonesonde measurements in the tropics following convective activity also show very low concentrations of $\mathrm{O}_{3}$ in the upper troposphere. These low amounts are attributed to vertical injection of ozone poor oceanic boundary layer air during convection into the upper troposphere followed by convective outflow. Over South America and Africa, $\mathrm{O}_{3}$ mixing ratios inside deep convective clouds often exceed $50 \mathrm{ppbv}$ which are comparable to mean back-
\end{abstract}

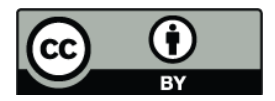

Correspondence to: J. R. Ziemke (jerald.r.ziemke@nasa.gov) ground (cloud-free) amounts and are consistent with higher concentrations of injected boundary layer/lower tropospheric $\mathrm{O}_{3}$ relative to the remote Pacific. The Atlantic region in general also consists of higher amounts of $\mathrm{O}_{3}$ precursors due to both biomass burning and lightning. Assuming that $\mathrm{O}_{3}$ is well mixed (i.e., constant mixing ratio with height) up to the tropopause, we can estimate the stratospheric column $\mathrm{O}_{3}$ over clouds. Stratospheric column ozone derived in this manner agrees well with that retrieved independently with the Aura Microwave Limb Sounder (MLS) instrument and thus provides a consistency check of our method.

\section{Introduction}

Satellite measurements of emitted thermal infrared (IR) radiances and backscattered sunlight in the ultraviolet (UV) and visible have different sensitivities to cloud properties, particularly for tropical deep convective clouds. Since clouds are highly absorbing/emitting in thermal IR bands, satellite IR sensors are sensitive to the temperature near the tops of these clouds. The IR cloud emissivity approaches unity at a visible optical depth of about 5 . Using temperature/pressure profiles, estimates of the cloud top pressure can be obtained with the $\mathrm{CO}_{2}$ slicing approach (e.g. Menzel et al., 1992).

In contrast, radiative transfer calculations based on optical depth profiles from the CloudSat radar suggest that visible light penetrates much deeper into tropical convective clouds

Published by Copernicus Publications on behalf of the European Geosciences Union. 
(Vasilkov et al., 2008). Estimates of UV/visible photon path lengths in cloudy conditions can be derived from oxygen $\left(\mathrm{O}_{2}\right)$ A-band absorption (e.g., Rozanov et al., 2004), oxygen dimer $\left(\mathrm{O}_{2}-\mathrm{O}_{2}\right)$ absorption (e.g., Sneep et al., 2007), or rotational-Raman scattering in the UV (Joiner and Bhartia, 1995). The latter two approaches have been implemented with the Dutch-Finnish Ozone Monitoring Instrument (OMI) flying on NASA's Earth Observing System (EOS) Aura satellite. The retrieved OMI cloud pressures for bright tropical deep convective clouds represent the equivalent Lambertian pressure required to produce the observed amount of oxygen dimer absorption or rotational-Raman scattering. We refer to this cloud pressure as the optical centroid cloud pressure (OCCP).

Vasilkov et al. (2008) showed that OMI OCCPs of deep convective clouds are typically several hundred $\mathrm{hPa}$ inside the cloud and are consistent with vertical optical depth profiles derived from the combination of CloudSat radar reflectivity data and MODIS-derived optical depth. Differences between the IR-derived cloud-top pressure and the OCCP can be attributed to enhanced scattering within the clouds, the presence of multiple cloud decks, and sensitivity to cloud geometrical thickness (e.g., Rozanov et al., 2004). In this paper we show that cloud vertical inhomogeneity also contributes to these differences. Specifically, we expand on the work of Vasilkov et al. (2008) by examining the vertical dependence of ozone absorption within realistic tropical deep convective clouds.

Here, we use a strict data selection criteria (pixels with reflectivity $>=80 \%$ ). This ensures that we have selected only pixels with cloud fractions of unity that contain deep convective towers. We do not consider pixels with cloud fractions less than one or pixels with thin clouds, such as those covering cirrus outflow regions, that would result in reflectivities less than $80 \%$. Comparisons with CloudSat data confirm that pixels with reflectivities $>80 \%$ correspond to deep convective tower clouds and that these clouds tend to be relatively homogeneous over an OMI pixel (see Vasilkov et al., 2008 for examples). These cases are important for the calculation of shortwave tropospheric ozone radiative forcing. The sensitivity of shortwave radiative forcing to tropospheric ozone is high over bright surfaces such as deep convective towers due to enhanced atmospheric photon pathlength.

Our study utilizes the OCCP concept along with measured column ozone from OMI to derive ozone mixing ratios inside tropical deep convective clouds. Two methods of measurement are invoked. The first is similar to the cloud slicing concept proposed by Ziemke et al. (2001). This method assumes a uniform $\mathrm{O}_{3}$ mixing ratio inside clouds within a confined geographical region. Inside the region an ensemble of pixels is used to derive the in-cloud $\mathrm{O}_{3}$ mixing ratio from the slope of measured $\mathrm{O}_{3}$ column versus OCCP. The second method incorporates a residual approach (e.g., Fishman et al., 1990) to determine $\mathrm{O}_{3}$ in thick clouds by combining $\mathrm{O}_{3}$ measurements from OMI and the Microwave Limb Sounder
(MLS) instrument on Aura. Because ozonesondes are not launched directly into deep convective clouds, these satellite measurements provide a unique means to determine $\mathrm{O}_{3}$ concentrations inside thick clouds throughout the tropics.

This paper is organized as follows: Sect. 2 details the OMI instrument and data sets. Sect. 3 discusses the sensitivity of UV radiance measurements to $\mathrm{O}_{3}$ inside deep convective clouds, and Sect. 4 describes the cloud slicing and residual $\mathrm{O}_{3}$ algorithms. Sect. 5-7 discuss the retrievals of $\mathrm{O}_{3}$ in-cloud mixing ratios and their implications. Finally, Sect. 8 provides a summary.

\section{The Ozone Monitoring Instrument: specifications and data sets}

OMI is a UV/VIS nadir-viewing solar backscatter spectrometer that makes daily measurements of Earth radiances and solar irradiances from 270 to $500 \mathrm{~nm}$ with a spectral resolution of approximately $0.5 \mathrm{~nm}$ (Levelt et al., 2006). The UV channel consists two subchannels: The UV-1 with the range $270-310 \mathrm{~nm}$ and UV-2 that covers $310-365 \mathrm{~nm}$. The total ozone and cloud parameters used in this work were derived using the UV-2 channel that provides near global coverage with a nadir pixel size of $13 \mathrm{~km} \times 24 \mathrm{~km}$. Retrievals of column amounts of $\mathrm{O}_{3}$ and other trace gases as well as cloud and aerosol properties are provided by observations in these channels.

There are two standard OMI total ozone products. Here we use data from the OMTO3 collection 3 v8.5 product that is based on the Total Ozone Mapping Spectrometer (TOMS) v8 total $\mathrm{O}_{3}$ algorithm. A description of this algorithm may be obtained from the TOMS v8 CD DVD ROM or from the OMI Algorithm Theoretical Basis Document (ATBD). The TOMS ATBD can be read and/or downloaded from the TOMS web page http://toms.gsfc.nasa.gov/ version8/v8toms_atbd.pdf. The OMTO3 total column ozone retrievals have been compared extensively with groundbased data (McPeters et al., 2008) and aircraft-based measurements (Kroon et al., 2008a).

Another OMI algorithm based on the Differential Optical Absorption Spectroscopy Method (DOAS) technique gives similar estimates of total column ozone (Kroon et al., 2008b). As with the OMTO3 v8.5 algorithm, actual cloud pressures are used in the DOAS algorithm to measure total ozone and other trace gases. All satellite DOAS techniques as applied to GOME, SCIAMACHY, OMI, and GOME2 satellite data derive total column amounts using cloud parameters retrieved with the same instrument (e.g., Coldewey-Egbers et al., 2005; Eskes et al., 2005; Roozendael et al., 2006; Kroon et al., 2008b).

There are two OMI algorithms that determine the OCCP. One is based on $\mathrm{O}_{2}-\mathrm{O}_{2}$ dimer absorption (Sneep et al., 2008). The other is based on rotational-Raman scattering (RRS) which creates spectral structures in the ratio of backscattered 
radiance to the solar irradiance known as the Ring effect (Joiner and Bhartia, 1995; Joiner et al., 2004; Joiner and Vasilkov, 2006). The two OMI cloud algorithms provide similar estimates of OCCP for bright clouds although there are small differences due to algorithmic and physical effects (Sneep et al., 2008).

One main difference between the TOMS $\mathrm{v} 8$ and the OMTO3 v8.5 algorithms is the treatment of clouds. The TOMS v8 and earlier versions of OMTO3 use a cloud pressure climatology based on thermal infrared cloud-top pressures, while the OMTO3 v8.5 uses OCCP derived with OMI by the RRS method. The use of simultaneouslyderived OCCP significantly improves estimates of total column ozone, especially in the presence of bright clouds (Joiner et al., 2006). Here, we use the measured column ozone amounts as opposed to estimates of the total column ozone. The measured column amounts do not include the unmeasured $\mathrm{O}_{3}$ column below the OCCP (also known as the "ghost column") that is traditionally added to provide estimates of the total column $\mathrm{O}_{3}$ (from top of the atmosphere to the surface).

\section{Sensitivity of $\mathrm{UV}$ to $\mathrm{O}_{3}$ inside deep convective clouds}

Most previous radiative transfer simulations of UV/visible light in cloudy conditions have been conducted with vertically homogeneous clouds. Recently, the combination of the CloudSat profiling radar reflectivities (Stephens et al., 2002) with collocated Aqua MODIS optical depth retrievals (Platnick et al., 2003) has been used to produce estimates of cloud optical depth vertical profiles. Vasilkov et al. (2008) used such profiles to validate OMI optical centroid cloud pressures from the rotational-Raman technique in a tropical deep convective complex. This study uses the same optical depth profiles (tropical Pacific, 13 November 2006, CloudSat granule 2906 and OMI orbit 12402) to examine photon penetration and $\mathrm{O}_{3}$ absorption inside bright vertically-inhomogeneous clouds. We use the Linearized Discrete-Ordinate Radiative Transfer LIDORT-RRS code (Spurr et al., 2007) for all calculations. The details of radiative transfer simulation are described in Vasilkov et al. (2008).

The left side of Fig. 1 shows a single CloudSat/MODISderived optical depth profile for a tropical deep convective cloud with a cloud optical thickness of 57 . The optical depth per unit length has a large peak near $400 \mathrm{hPa}$ corresponding to the ice portion of the cloud with a smaller peak in the water part of the cloud near $600 \mathrm{hPa}$.

The right side of Fig. 1 shows $\mathrm{O}_{3}$ Jacobians computed using 1) the CloudSat/MODIS optical depth profile and 2) a Lambertian-equivalent reflectivity model with the surface placed at the optical centroid cloud pressure. The Lambertian cloud model produces the same amount of rotationalRaman scattering at $350 \mathrm{~nm}$ as that simulated for the CloudSat/MODIS optical depth profile. The OMI retrieved optical
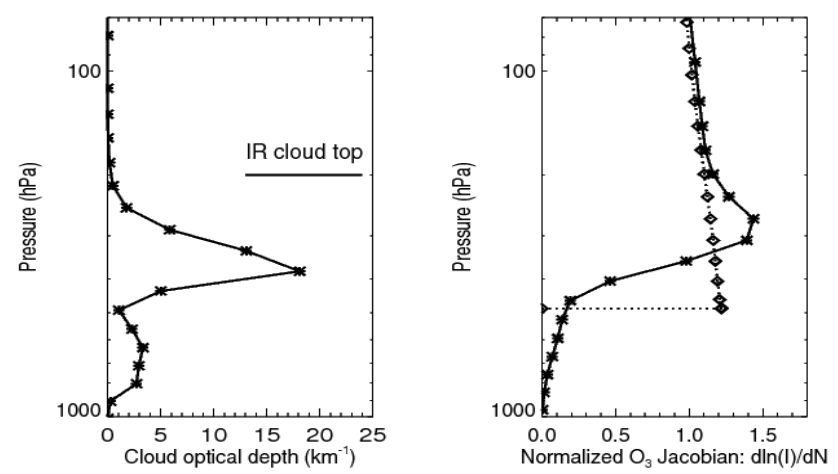

Fig. 1. Left: Cloud optical depth profile from CloudSat/MODIS and approximate MODIS cloud-top pressure from a tropical sounding on 13 November 2006. Right: Normalized ozone Jacobians (partial derivative of the natural logarithm of the radiance at $322.9 \mathrm{~nm}$ with respect to the ozone optical depth - normalized to unity in the stratosphere) computed using CloudSat/MODIS optical depth profile (solid line with stars) and for a Lambertian cloud located at the optical centroid pressure (dotted line with diamonds).

centroid cloud pressure was very close to the simulated value (Vasilkov et al., 2008). The Jacobians were computed using a $5 \%$ perturbation in $\mathrm{O}_{3}$ optical depth per layer. They are plotted as a change in natural logarithm of the radiance per unit change in layer ozone optical depth normalized to a value of unity in the stratosphere.

The Jacobian indicates enhanced $\mathrm{O}_{3}$ absorption starting near the physical cloud top and extending well inside the cloud to a pressure near $300 \mathrm{hPa}$. The sensitivity then decreases near the optical depth peak at $\sim 400 \mathrm{hPa}$. There is relatively little radiance sensitivity to $\mathrm{O}_{3}$ absorption in the water portion of this cloud.

CloudSat radar reflectivity data show that this cloud extends to pressures near $200 \mathrm{hPa}$ (see Vasilkov et al., 2008); The CloudSat/MODIS optical depth profile retrievals show that the extinction near the cloud top is small. The MODIS cloud-top pressure derived from the $\mathrm{CO}_{2}$ slicing method is also $\sim 200 \mathrm{hPa}$ for this case (Vasilkov et al., 2008).

Figure 2 similarly shows an optical depth profile with a peak near $600 \mathrm{hPa}$ and a total optical depth of 44.6 along with computed Jacobians. Here, the enhanced ozone sensitivity occurs between $\sim 250-450 \mathrm{hPa}$ with sensitivity dropping off near the optical depth peak at $\sim 600 \mathrm{hPa}$. As in the case of the profile in Fig. 1, CloudSat data showed that the physical top of this cloud was also near $200 \mathrm{hPa}$. Again, MODIS reported a cloud-top very close to that given by CloudSat.

Figure 3 shows that the cloud optical depth profiles in Figs. 1 and 2 are typical of tropical deep convection. In this figure, we computed the mean cloud optical depth profile on 13 November 2006 for two different ranges of cloud optical thickness. The brightest tropical clouds $(\mathrm{COT}>50)$ on average have a peak near $400 \mathrm{hPa}$ similar to the profile shown in Fig. 1. Less bright clouds $(30<\mathrm{COT}<50)$ peak near the 

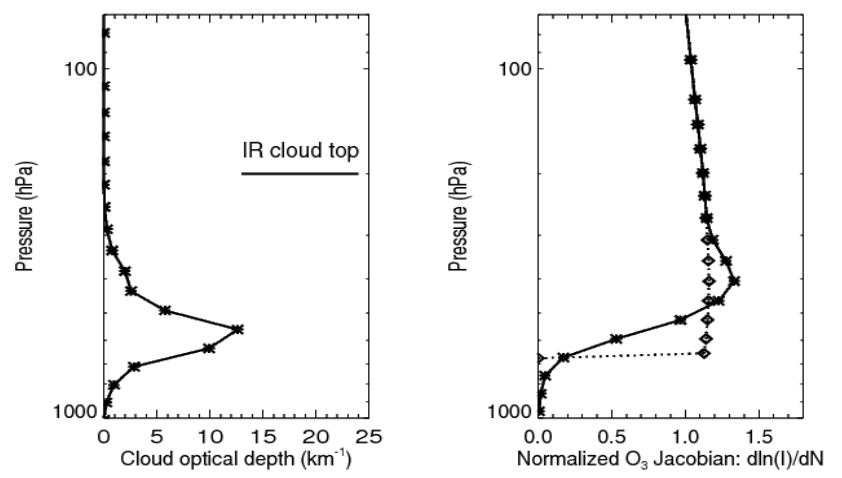

Fig. 2. Similar to fig. 1, but for a different CloudSat/MODIS pixel.

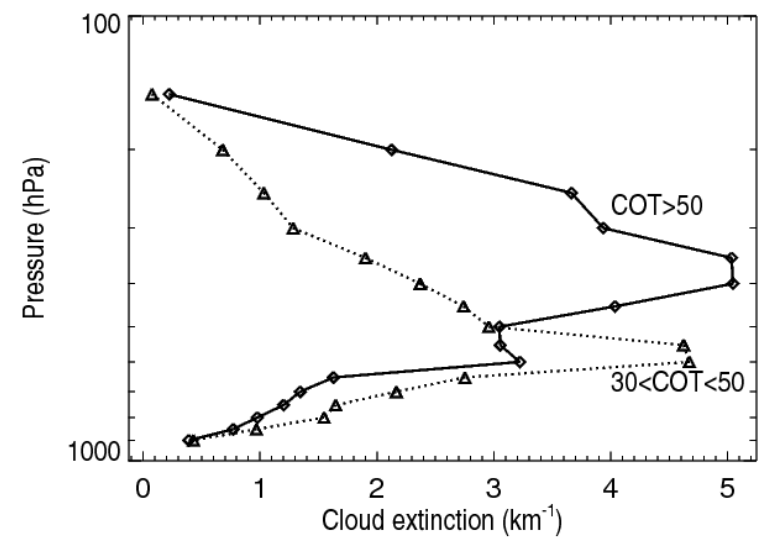

Fig. 3. Mean tropical cloud optical depth profiles derived from CloudSat/MODIS data on 13 November 2006 for different ranges of cloud optical thickness (COT).

melting point $(\sim 600 \mathrm{hPa})$ similar to the profile in Fig. 2 . The cloud-top pressures retrieved with the MODIS $\mathrm{CO}_{2}$ slicing method for the profiles shown in Figs. 1 and 2 (and in general for tropical deep convection) are $\sim 200 \pm 25 \mathrm{hPa}$ and close to the physical cloud top as detected by CloudSat. Figure 3 indicates that on average, deep convective clouds are optically thin near their tops. This allows for significant photon penetration as shown in Figs. 1 and 2.

We can evaluate the Lambertian cloud model by computing the integral over pressure of the Jacobian between the surface and the tropopause and comparing with that for the exact CloudSat/MODIS profile. The two cloud profiles produce the same amount of rotational-Raman scattering at $350 \mathrm{~nm}$ by definition. Assuming a constant ozone mixing ratio throughout the troposphere, the integrated Jacobians are inversely proportional to the tropospheric ozone mixing ratio. Therefore, the ratio of the two integrals reflects the tropospheric ozone mixing ratio error. The errors for the profiles in Figs. 1 and 2 are $7 \%$ and 14\%, respectively. Note that the errors could be either larger or smaller for non-uniform ozone mixing ratios.

\section{CLOUD SLICING MEASUREMENTS OF OZONE INSIDE THICK CLOUDS}

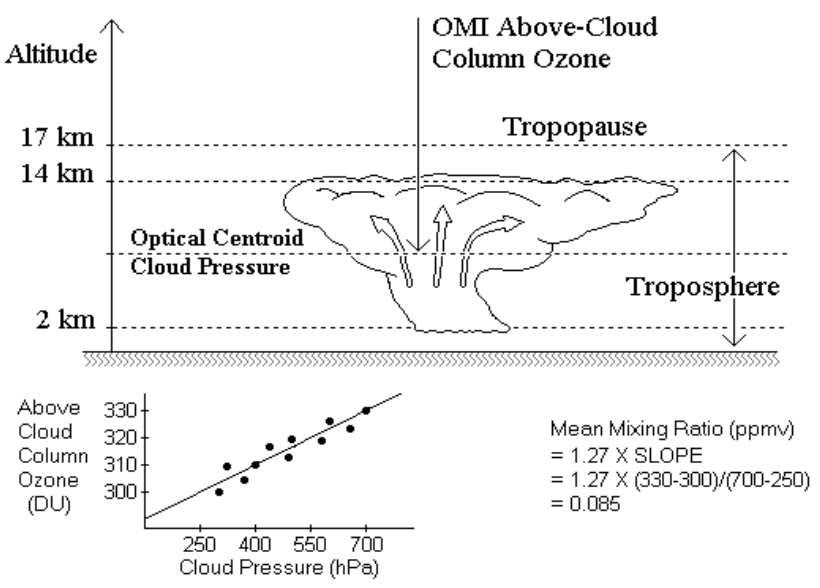

Fig. 4. Schematic diagram illustrating the ensemble cloud-slicing method. The figure shows that a satellite UV instrument is sensitive to the $\mathrm{O}_{3}$ column from the top of the atmosphere down to the OCCP altitude which may lie several hundred $\mathrm{hPa}$ below geometrical cloud top. The lower half of the figure illustrates that using an ensemble of such measurements over a fixed region, mean volume mixing ratio can be determined from the slope of column $\mathrm{O}_{3}$ plotted versus OCCP.

\section{Retrieval of tropospheric ozone in thick clouds using the ensemble cloud slicing and residual methods}

As noted in the Introduction, we invoke two methods for measuring tropospheric $\mathrm{O}_{3}$ in thick clouds from satellite remote sensing. One is the ensemble cloud slicing method (Ziemke et al., 2001) and the other incorporates the residual technique of Fishman et al. (1990). There are distinct advantages with both of these methods. For cloud slicing, an important advantage is that only one satellite instrument is required, while for the residual method one can obtain very high horizontal resolution measurements.

Ensemble cloud slicing is used to directly estimate ozone volume mixing ratio (VMR) inside convective clouds. Figure 4 shows how this method works schematically. A typical measurement of column $\mathrm{O}_{3}$ from OMI extends down to the OCCP that lies well below the physical cloud top. Over a selected region (here we use $5^{\circ}$ latitude $\times 5^{\circ}$ longitude boxes), the slope of measured column $\mathrm{O}_{3}$ versus OCCP from an ensemble of coincident measurements yields mean VMR. Explicitly, VMR (units ppmv) $=1.27 \times$ SLOPE, where SLOPE is measured in Dobson Units (DU; $1 \mathrm{DU}$ $\equiv 2.69 \times 10^{20}$ molecules per $\mathrm{m}^{2}$ ) per $\mathrm{hPa}$. OMI reflectivities $R>0.6$ coincide generally with deep clouds and scene cloud radiance fractions of $100 \%$. This study uses a more stringent criterion of $R>0.8$, typical of deep convective clouds, for all calculations. 

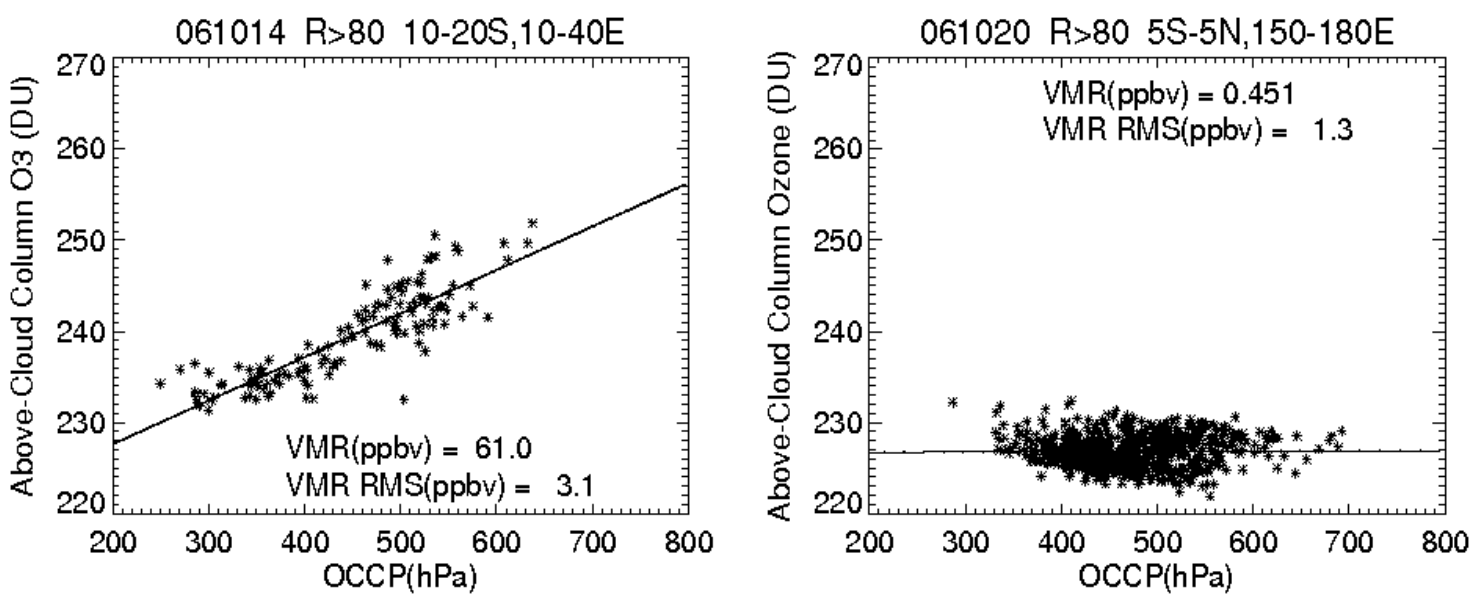

Fig. 5. Daily scatter plots of $\mathrm{O}_{3}$ column versus OCCP in October 2006. Left panel: southern Africa on 14 October 2006 . Right panel: western Pacific on 20 October 2006. Both mean VMR and its RMS uncertainty ( $\sigma$, in ppbv) from the regression line fitting are shown.

One feature of the cloud slicing approach is that it is not necessary to have an estimate of the stratospheric column ozone (SCO) amount because it cancels out in the slope of the measured column ozone versus OCCP. However, SCO can be derived from the ensemble cloud-slicing technique by extrapolating the linear fit to the tropopause pressure. A main assumption for the ensemble cloud slicing method is that both stratospheric column ozone and tropospheric mean mixing ratio do not vary much over the ensemble region. The method in principle may be applied outside the tropics provided that this requirement is adequately satisfied (Ahn et al., 2003; Ziemke et al., 2003).

One cannot directly compare the spatial and temporal characteristics of $\mathrm{O}_{3}$ determined in this study with that from the cloud slicing approach of Ziemke et al. (2001, 2003) which utilized infrared-derived cloud-top pressures. There are fundamental differences in the pixel sample and in the physical properties of the clouds in the selected pixels used to dertermine upper tropospheric $\mathrm{O}_{3}$ in the different studies. Here we incorporate only exceedingly deep convective clouds (reflectivity $>0.8$ ) and derive an optical centroid cloud pressure that lies many km below the geometrical cloud top. In contrast, the IR cloud top pressures used by Ziemke et al. $(2001,2003)$ lie much closer to the actual geometrical cloud top and used much more relaxed scene reflectivity constraints of 0.6 and 0.44 , respectively. These lower limits were necessary to gather enough measurements for analysis. If only deep convective clouds are selected, the IR-derived cloud top pressures do not contain enough variability to accurately estimate tropospheric ozone. As a result of the relaxed reflectivity criteria, many of the selected pixels coincided not with deep convective clouds, but often only moderately convective clouds and pixels with a mixture of different cloud types including clouds with geometrical cloud tops far below the tropopause. Note also that the Nimbus 7 TOMS has a much larger footprint size $(\sim 50 \mathrm{~km}$ diam- eter at nadir) than OMI. However, if the slope of the column ozone versus the cloud pressure is similar when using the IR cloud-top pressure as compared with the UV OCCP, the derived tropospheric ozone mixing ratio will be comparable although there will be a significant pressure offset difference.

Tropospheric ozone can also be derived in thick clouds from the residual method in which an estimate of SCO must be provided. The residual method has been applied to TOMS using estimates of SCO from the convective cloud differential (CCD) method (Ziemke et al., 1998). The residual approach has also been applied to OMI using SCO from the Aura Microwave Limb Sounder (MLS) (Ziemke et al., 2006; Schoeberl et al., 2007). The residual method can in principal be applied in both clear and cloudy conditions. In cloudy conditions we can make use of the OCCP concept. In this way an estimate of the tropospheric ozone mean mixing ratio can be obtained for every pixel.

\section{Results from the ensemble cloud slicing method}

Figure 5 shows scatter plots of measured column $\mathrm{O}_{3}$ versus OCCP over southern Africa and in the western Pacific for selected days in October 2006. $\mathrm{O}_{3}$ VMR in the western Pacific is essentially zero while over southern Africa the concentration is $\sim 60$ ppbv. Enhanced $\mathrm{O}_{3}$ over southern Africa suggests that $\mathrm{O}_{3}$ produced from regional pollution including biomass burning, which is largest around September-October each year, reaches the upper regions of the clouds. The elevated $\mathrm{O}_{3}$ may be caused by other sources, e.g., lightning, and transport effects including the planetary-scale Walker circulation. The near-zero $\mathrm{O}_{3}$ VMR in the western Pacific is consistent with values measured in the vicinity of convection by ozonesondes (e.g., Kley et al., 1996; Folkins et al., 2002; Solomon et al., 2005). The VMRs for the selected days in 

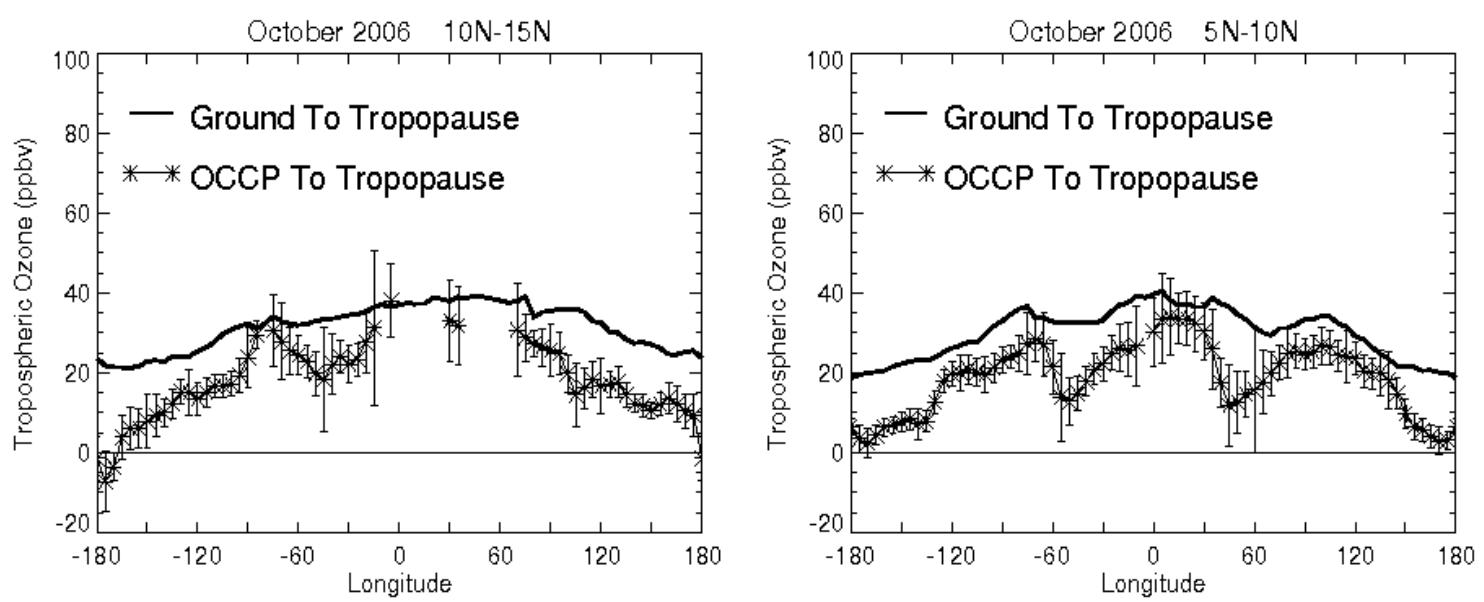

Fig. 6. Tropospheric $\mathrm{O}_{3}$ VMR from OMI as a function of longitude for thick-clouds (indicated by asterisks) in two tropical latitude bands in October 2006. Values for VMR include $\pm 2 \sigma$ regression uncertainties (values for $\sigma$ represent standard error of the mean). The solid curves represent VMR for nearly cloud-free sky (reflectivity $<0.2$ ) from the CCD method (see text). Data are for $5^{\circ} \times 5^{\circ}$ regions averaged over the month from daily measurements and for OMI include a 3-point running average smoothing along longitude.
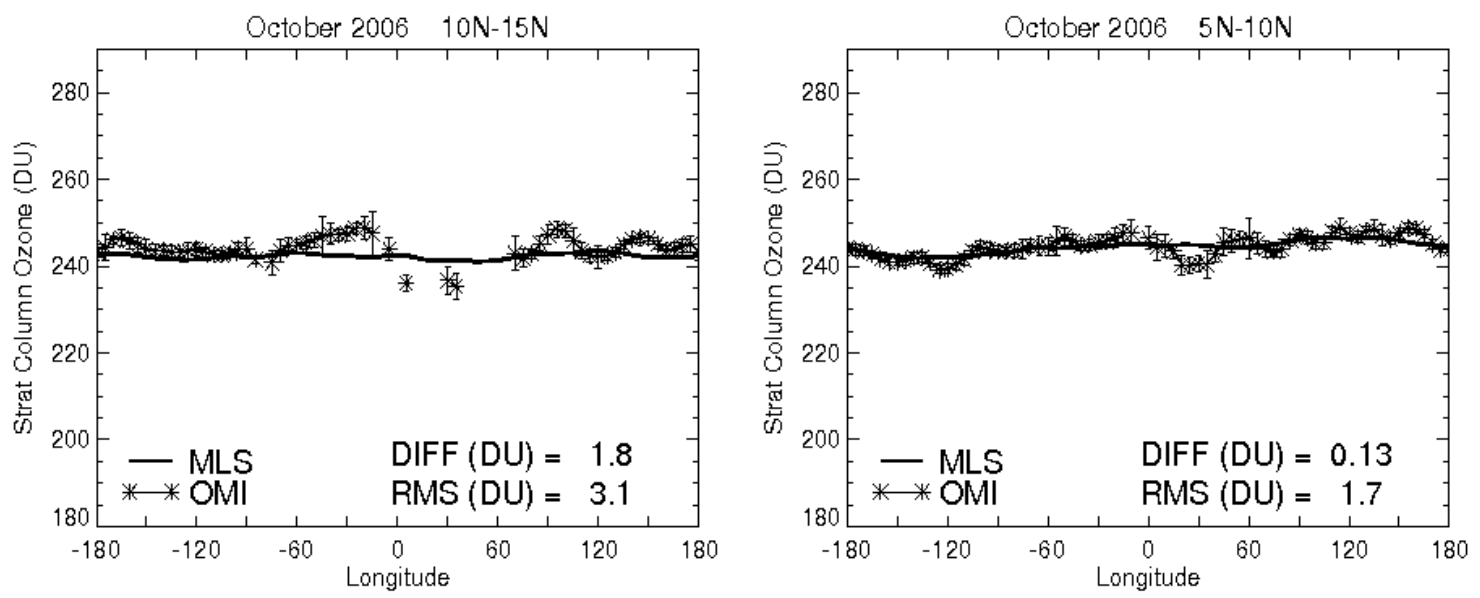

Fig. 7. SCO (in DU) versus longitude in two tropical latitude bands for October 2006. Asterisks: SCO derived from OMI using thick clouds; Solid lines: SCO from MLS. Error bars are $\pm 2 \sigma$ uncertainties (values for $\sigma$ represent standard error of the mean). Mean difference (OMI minus MLS) and zonal RMS of the difference in DU are listed in both panels. Data are for $5^{\circ} \times 5^{\circ}$ regions averaged over the month from daily measurements and for OMI include a 3-point running average smoothing along longitude.

Fig. 5 are typical of all other days during October 2006 for both regions.

Zonal variability of in-cloud VMR is shown in Fig. 6 for October 2006. Data are for $5^{\circ} \times 5^{\circ}$ regions averaged over the month from daily measurements and for OMI include a 3point running average smoothing along longitude. The two latitude bands $\left(10^{\circ} \mathrm{N}-15^{\circ} \mathrm{N}\right.$ and $\left.5^{\circ} \mathrm{N}-10^{\circ} \mathrm{N}\right)$ shown in this figure lie within or near the Inter-tropical Convergence Zone (ITCZ) where deep clouds occur frequently. Figure 6 also shows the corresponding zonal variability of mean equivalent VMR for nearly cloud-free scenes (reflectivity $R<0.2$ ). This cloud-free VMR is derived from tropospheric column $\mathrm{O}_{3}$ (measured in DU) using the CCD method. (The CCD method and its validity are discussed in Sect. 6.) The con- version from column $\mathrm{O}_{3}$ to mean equivalent VMR (in units ppmv) is obtained by dividing the tropospheric $\mathrm{O}_{3}$ column in DU by total differential pressure (surface pressure minus the tropopause pressure) in $\mathrm{hPa}$ followed by multiplying this number by 1.27 (e.g., Ziemke et al., 2001, and references therein).

Figure 6 indicates that the zonal variability in $\mathrm{O}_{3}$ VMR inside the deep clouds is qualitatively similar to cloud-free scenes. However, absolute values of $\mathrm{O}_{3}$ VMR in the cloudfree scenes are larger than the corresponding values inside thick clouds most everywhere. This is particularly apparent in the Pacific region where the $\mathrm{O}_{3}$ VMR values under cloudy conditions are close to zero. 


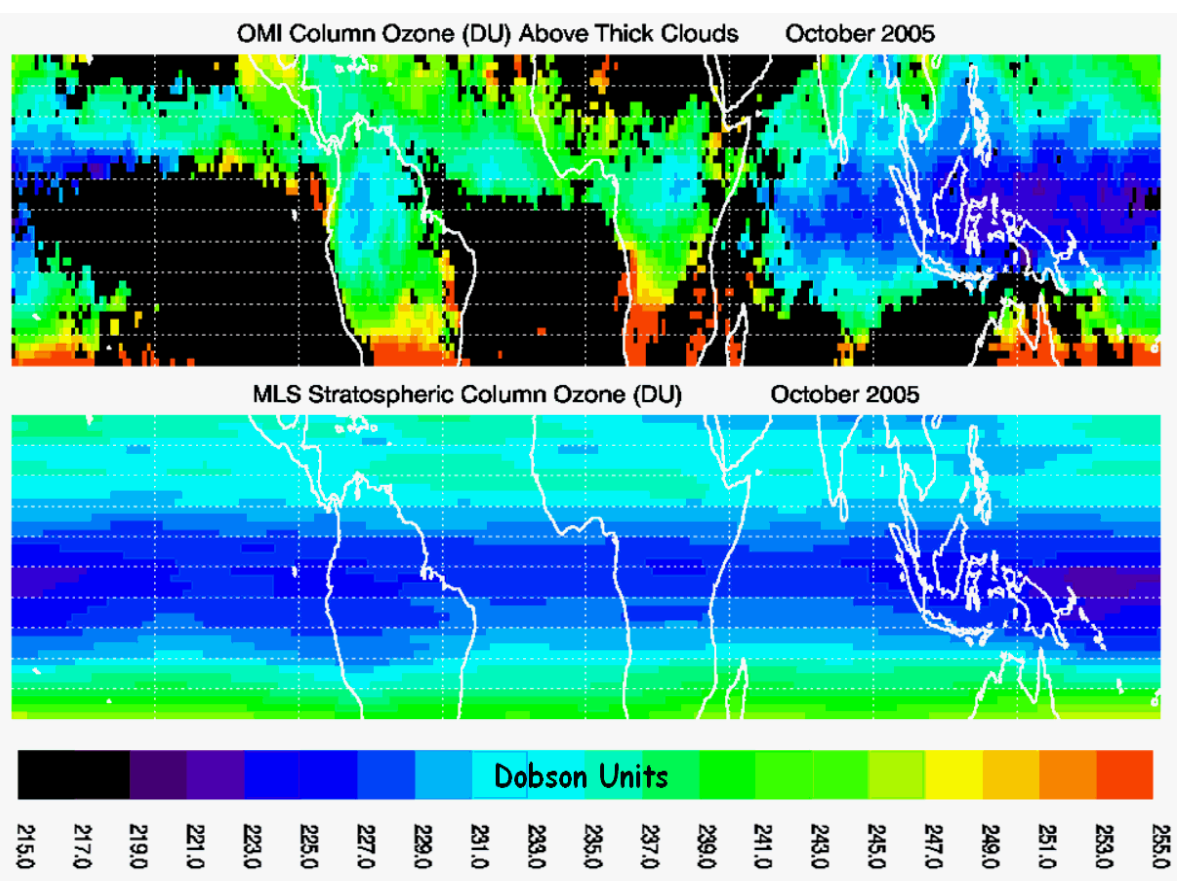

Fig. 8. Measured column $\mathrm{O}_{3}$ from Aura OMI (top panel) and SCO from the Aura MLS instrument (bottom panel) averaged for October 2005. Column amounts for both OMI and MLS were binned to $1^{\circ}$ latitude $\times 1.25^{\circ}$ longitude resolution from daily level-2 footprint measurements . $\mathrm{OMI} \mathrm{O}_{3}$ was filtered for conditions of bright clouds (scene reflectivity $R>0.8$ ), ECP $<750 \mathrm{hPa}$, and includes a 3-point running average smoothing along longitude and latitude. SCO was determined from spatially interpolated daily MLS data which were then averaged monthly. Black pixels over ocean and northern Africa in the top panel indicate no bright clouds in these regions for the entire month.

There are two components of information obtained from the linear fit of measured column $\mathrm{O}_{3}$ versus OCCP with the ensemble cloud slicing method. Mean VMR is derived from the slope, and SCO is estimated from the intercept. If we assume that $\mathrm{O}_{3}$ between OCCP and the tropopause is well mixed (i.e., constant VMR), we can then estimate SCO by extrapolating the linear fits to the tropopause pressure (taken everywhere to be $100 \mathrm{hPa}$ for tropical latitudes). The column amount at $100 \mathrm{hPa}$ is then an estimate of SCO.

Figure 7 compares zonal variability of SCO for October 2006 over thick clouds derived by cloud slicing using OMI (asterisks) with that derived from MLS under all conditions (thick curves). The Aura MLS measurements of SCO are described by Ziemke et al. (2006). The values shown for both OMI and MLS were first calculated from daily measurements in $5^{\circ} \times 5^{\circ}$ grid boxes and then averaged over the month. The OMI data include a 3-point running average smoothing along longitude.

SCO from MLS and OMI in Fig. 7 agrees remarkably well with mean differences of $\sim 1$ DU and zonal RMS differences of $\sim 2-3$ DU. Such good agreement can only be obtained if the measured ozone and the OCCP concept are correct. If we had asserted that OMI does not measure $\mathrm{O}_{3}$ below the physical cloud-tops as assumed previously by Ziemke et al. (1998), then we would still get the correct SCO in the Pacific because $\mathrm{O}_{3}$ inside these thick clouds is negligibly small. However, SCO values derived elsewhere by cloudslicing would be larger and show longitudinal variability that would be inconsistent with other satellite and sonde data. Hence, this SCO comparison provides an independent validation of the in-cloud VMR amounts (and thus of both the OCCP and $\mathrm{O}_{3}$ column from OMI) derived in this study.

\section{Results from the OMI/MLS residual method}

Figure 8 shows the measured column $\mathrm{O}_{3}$ from OMI (top panel) and SCO from the MLS instrument (bottom panel) for October 2005. Both column measurements were obtained from daily level-2 footprint measurements binned to $1^{\circ}$ latitude $\times 1.25^{\circ}$ longitude resolution. Here we use OMI measured column $\mathrm{O}_{3}$ values for pixels containing bright clouds with scene reflectivity $R>0.8$ and $\mathrm{OCCP}<750 \mathrm{hPa}$ with a 3-point running average smoothing along longitude and latitude. As in Ziemke et al. (2006), MLS SCO was determined from spatially interpolated daily data averaged over each month. The validation of $\mathrm{MLS} \mathrm{O}_{3}$ profile data is discussed by Froidevaux et al. (2008).

The two panels in Fig. 8 indicate nearly equal values of column $\mathrm{O}_{3}(\sim 220 \mathrm{DU})$ from OMI and MLS in the Pacific. However, the column amounts differ significantly outside of this region. The differences are due to a tropospheric 

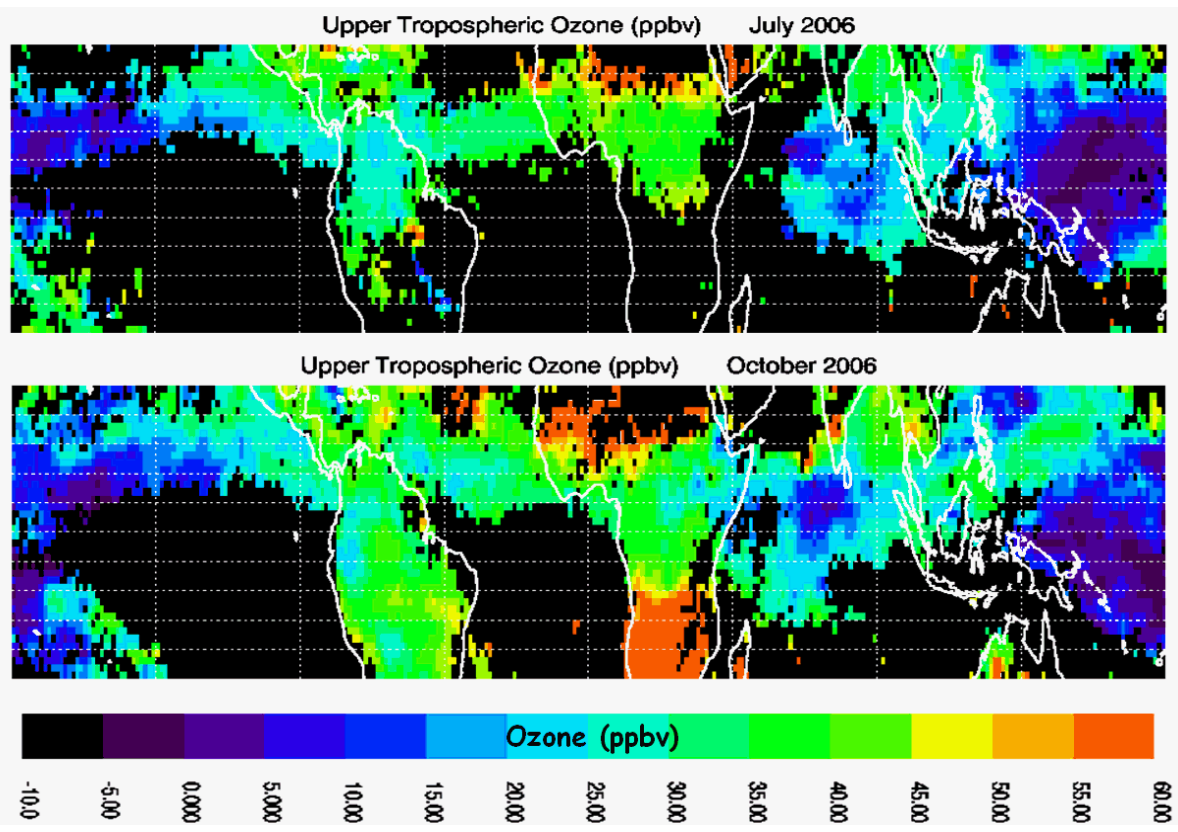

Fig. 9. Estimated mean upper tropospheric $\mathrm{O}_{3}$ VMR (ppbv) for July 2006 (top) and October 2006 (bottom). OCCP values were constrained to lie between $250 \mathrm{hPa}$ and $550 \mathrm{hPa}$. Column amounts were binned to $1^{\circ}$ latitude $\times 1.25^{\circ}$ longitude resolution from daily level- 2 footprint measurements which include a 3-point running average smoothing along longitude and latitude. Black pixels over ocean and northern Africa indicate no bright clouds in these regions for the entire months.

$\mathrm{O}_{3}$ contribution lying between tropopause and OCCP which varies from nearly zero DU in the Pacific to about $30 \mathrm{DU}$ over southern Africa and South America. SCO over the entire tropical region (lower panel) is nearly constant with values $\sim 225-230$ DU.

Figure 8 provides a foundation for the convective cloud differential (CCD) method that was originally based on two assumptions: (1) UV measuring instruments such as TOMS measure the ozone above the tops of highly reflective clouds; therefore SCO can be estimated using pixels that contain highly reflective clouds (reflectivity $R>0.8$ ) with cloud tops near the tropopause level in the tropical Pacific region, and (2) SCO is to first order zonally invariant within the latitude range $15^{\circ} \mathrm{S}$ to $15^{\circ} \mathrm{N}$. An important property of the CCD technique, which follows from the first assumption, is that cloud height information is not needed to derive tropospheric column ozone. The second assumption was based upon many years of $\mathrm{O}_{3}$ measurements from satellites and ozonesondes (e.g., Ziemke et al., 1998; Thompson et al., 2003). Tropospheric column ozone at any latitude and longitude is then calculated by differencing low reflectivity $(R<0.2)$ gridded total column ozone and high reflectivity $(R>0.8) \mathrm{SCO}$ from the Pacific region. Although we have shown here that the first assumption is not correct, the CCD method still provides an accurate estimate of $\mathrm{SCO}$ because the $\mathrm{O}_{3}$ VMR in the tropical Pacific inside deep convective clouds is exceedingly small to essentially zero. This study provides a new interpretation of the CCD method and shows why it worked as implemented previously.
The measured column $\mathrm{O}_{3}$ from OMI in Fig. 8 (top) is identically the sum of $\mathrm{SCO}$ and tropospheric column $\mathrm{O}_{3}$ lying between the tropopause and the OCCP. Thus taking the difference of the two maps (top panel minus bottom panel in Fig. 8) yields column $\mathrm{O}_{3}$ lying between OCCP and the tropopause. This column amount can then be converted to mean VMR as described earlier for Fig. 6. As generated in this fashion, maps of upper tropospheric $\mathrm{O}_{3}$ are shown in Fig. 9 for July and October 2006. OCCP values were constrained to lie between $250 \mathrm{hPa}$ and $550 \mathrm{hPa}$ to estimate mean $\mathrm{O}_{3}$ concentrations in the upper troposphere. As in Fig. 8 column amounts were binned to $1^{\circ}$ latitude $\times 1.25^{\circ}$ longitude resolution from daily level-2 footprint measurements and include a 3-point running average smoothing along longitude and latitude.

For July and October 2006 there are some pixels in the eastern and western Pacific that have negative VMRs of a few ppbv. As discussed by Ziemke et al. (2006), SCO from MLS is adjusted to OMI CCD measurements of SCO. The small localized values of negative $\mathrm{O}_{3}$ in the Pacific could be explained by yet unresolved measurement/calibration differences between OMI and MLS for bright cloud scenes.

Following the CCD calibration adjustment, the largest remaining problem with residual method is the remaining unresolvable precision errors. We've estimated that RMS precision uncertainty in daily level-2 residuals (OMI minus MLS) is about $7 \mathrm{DU}$ in tropical latitudes. Stratospheric column ozone in daily measurements from MLS associated with deep convective clouds has about a $3 \%$ precision RMS uncertainty ( $\sim 6.6 \mathrm{DU})$ while OMI RMS precision uncertainty is around 
$1 \%$ ( 2.6 DU). (These numbers assume $220 \mathrm{DU}$ and $260 \mathrm{DU}$ column amounts, respectively.) It follows that the estimated precision error of the OMI-MLS residual is then $\left[6.6^{2}+2.6^{2}\right]^{1 / 2} \approx 7 \mathrm{DU}$. The averaging of footprint measurements over time (such as a month in Figs. 8 and 9) and over a generally broad region $\left(1^{\circ}\right.$ latitude $\times 1.25^{\circ}$ longitude in Figs. 8 and 9) including additional 3-point running averaging reduces precision uncertainties to numbers considerably smaller than 7 DU. Standard error of the mean with 30 days of level-2 footprints in each box (with typically well more than 50 footprint measurements in each pixel box in the Pacific) and also averaging over 9 boxes (i.e., 3-point running average smoothing applied along both latitude and longitude) yields an RMS precision of the mean of $7 \mathrm{DU} /[30 \times 50 \times 9]^{1 / 2}$ which is about $0.06 \mathrm{DU}$.

\section{Discussion}

As mentioned in Sect. 5, studies of tropospheric $\mathrm{O}_{3}$ from ozonesonde measurements have shown occurrences of low to near-zero concentrations of $\mathrm{O}_{3}$ in the tropical upper troposphere (Kley et al., 1996; Folkins et al., 2002; Solomon et al., 2005). These low values are largely attributed to convective lifting of low amounts of $\mathrm{O}_{3}$ from the marine boundary layer into the upper troposphere. In pollution-free oceanic regions it is not uncommon for $\mathrm{O}_{3}$ in the marine boundary layer to be only a few ppbv owing to reactions involving hydrogen radicals $\mathrm{OH}$ and $\mathrm{HO}_{2}$ (e.g., Solomon et al., 2005, and references therein). Some studies have also suggested the possibility of in-cloud photochemical destruction mechanisms of $\mathrm{O}_{3}$ (e.g., Zhu et al., 2001; Barth et al., 2002; Liu et al., 2006). The previous inferences of near-zero concentrations of $\mathrm{O}_{3}$ in the tropical upper troposphere have been based almost entirely on ozonesondes and generally limited to a few isolated sites in the vicinity of (but not inside) deep convective cloud systems.

It is conceivable that the $\mathrm{O}_{3}$ mixing ratio distributions in Fig. 9 are largely a manifestation of air in the lower troposphere (including the planetary boundary layer) that is injected upward into the upper portions of clouds during convection. Exceedingly low $\mathrm{O}_{3}$ lies over the western Pacific extending across the dateline into the eastern Pacific along the ITCZ. Low amounts are also present in the Indian Ocean.

In contrast to the Pacific, elevated $\mathrm{O}_{3}$ occurs over the large land masses of Africa and South America in cloud free conditions as well as in the presence of deep convective clouds. The $\mathrm{O}_{3}$ concentrations exceed 50 ppbv over much of northern Africa in these months, and also southern Africa in October. These enhanced concentrations suggest a much more polluted environment including the boundary layer. There is also substantial amounts of tropospheric $\mathrm{O}_{3}$ for thick clouds extending from west of Central America eastward across the Atlantic to northern Africa in all months. The $\mathrm{O}_{3}$ VMRs for these thick clouds over ocean have values of $\sim 30-40$ ppbv.
October 2006 coincided with a strong El Nino event which contributed to the elevated tropospheric $\mathrm{O}_{3}$ seen in the western Pacific (Logan et al., 2008). While the dynamical changes (i.e., reduced convection during $\mathrm{El} \mathrm{Nino)} \mathrm{in} \mathrm{the}$ western Pacific increased $\mathrm{O}_{3}$ concentrations, some of the increases were also caused by lightning and biomass burning in Indonesia in October.

\section{Summary}

In this paper we have developed a new technique for deriving tropospheric ozone mixing ratios inside deep convective clouds and the stratospheric column ozone (SCO) lying above these clouds. The technique makes use of the concept of the optical centroid cloud pressure (OCCP) obtained from the effects of rotational-Raman scattering in the OMI UV spectra. We applied a radiative transfer model (LIDORTRRS) to study UV photon penetration and $\mathrm{O}_{3}$ absorption within deep convective clouds. The calculations are based upon realistic cloud optical depth profiles in tropical deep convective clouds from CloudSat and MODIS data. The calculations show that tropospheric $\mathrm{O}_{3}$ sensitivity at UV wavelengths for deep convective clouds is largest within the upper portion of these clouds with significant sensitivity above the cloud optical depth peak, but still well below the physical cloud top. Cloud optical depth typically peaks near $400 \mathrm{hPa}$ for the brightest clouds and near $600 \mathrm{hPa}$ for less bright convective clouds.

Assuming well-mixed tropospheric $\mathrm{O}_{3}$ (i.e., constant mixing ratio), we estimated SCO above thick clouds. The close agreement with SCO derived independently from Aura MLS and OMI provides an internal consistency check of measured $\mathrm{O}_{3}$ column amounts, the derived optical centroid cloud pressures, and thus the derived in-cloud $\mathrm{O}_{3}$ mixing ratios. Our study indicates very low and even near-zero $\mathrm{O}_{3}$ in the middleto-upper troposphere over much of the tropical Pacific region. These values are consistent with previous studies based on ozonesonde measurements made in close proximity to regions of convective activity.

In contrast to the Pacific region, $\mathrm{O}_{3}$ mixing ratios are significantly elevated (often exceeding $50 \mathrm{ppbv}$ ) over the large landmasses of Africa and South America. The larger concentration of $\mathrm{O}_{3}$ over these landmasses is consistent with larger amounts of $\mathrm{O}_{3}$ in the lower troposphere including boundary layer injected into deep convective clouds. Africa and South America including the broad connecting Atlantic each year have intense surface biomass burning (dry season over landmass) and lightning generated $\mathrm{NO}_{\mathrm{X}}$ (wet season, mostly over landmass) which both contribute to the generation of tropospheric $\mathrm{O}_{3}$. While surface biomass burning is largely a local source of $\mathrm{O}_{3}$ (when there is no significant transport to loft the precursors), cloud lightning $\mathrm{NO}_{\mathrm{X}}$ is well known to produce large concentrations of $\mathrm{O}_{3}$ throughout the Atlantic from advection with a photochemical time delay of many weeks. It 
is also well known from past studies that transport including the Walker Circulation re-distributes tropical $\mathrm{O}_{3}$ to yield enhanced concentrations over the Atlantic compared to Pacific. Future work, beyond the scope of this study, is to delineate the various contributing sources of the observed $\mathrm{O}_{3}$ distributions in the tropics under conditions of deep convective clouds.

Acknowledgements. The authors thank the Aura OMI and MLS instrument and algorithm teams for the extensive satellite measurements used in this study. The OMI instrument was built by Dutch-Finnish collaboration, and is managed by the Royal Netherlands Meteorological Institute (KNMI). Data used in this study were processed at NASA Goddard Space Flight Center. Funding for this research was provided in part by Goddard Earth Science Technology (GEST) grant NGC5-494.

Edited by: G. Vaughan

\section{References}

Acarreta, J. R., De Haan, J. F., and Stammes, P.: Cloud pressure retrieval using the $\mathrm{O}_{2}-\mathrm{O}_{2}$ absorption band at $477 \mathrm{~nm}$, J. Geophys. Res., 109(D5), D05204, doi:10.1029/2003JD003915, 2004.

Ahn, C., Ziemke, J. R., Chandra, S., and Bhartia, P. K.: Derivation of tropospheric column ozone from EPTOMS/GOES co-located data sets using the Cloud Slicing technique, J. Atmos. Sol.-Ter. Phy., 65(10), 1127-1137, 2003.

Barth, M. C., Hess, P. G., and Madronich, S.: Effect of marine boundary layer clouds on tropospheric chemistry as analyzed in a regional chemistry transport model, J. Geophys. Res., 107(D11), 4126, doi:10.1029/2001JD000468, 2002.

Coldewey-Egbers, M., Weber, M., Lamsal, L. N., de Beek, R., Buchwitz, M., and Burrows, J. P.: Total ozone retrieval from GOME UV spectral data using the weighting function DOAS approach, Atmos. Chem. Phys., 5, 1015-1025, 2005, http://www.atmos-chem-phys.net/5/1015/2005/.

Eskes, H. J., van der A, R. J., Brinksma, E. J., Veefkind, J. P., de Haan, J. F., and Valks, P. J. M.: Retrieval and validation of ozone columns derived from measurements of SCIAMACHY on Envisat, Atmos. Chem. Phys. Discuss., 5, 4429-4475, 2005, http://www.atmos-chem-phys-discuss.net/5/4429/2005/.

Fishman, J., Watson, C. E., Larsen, J. C., and Logan, J. A.: Distribution of tropospheric ozone determined from satellite data, J. Geophys. Res., 95(D4), 3599-3617, 1990.

Folkins, I., Braun, C., Thompson, A. M., and Witte, J.: Tropical ozone as an indicator of deep convection, J. Geophys. Res., 107(D13), 4184, doi:10.1029/2001JD001178, 2002.

Froidevaux, L., Jiang, Y. B., Lambert, A., et al.: Validation of Aura Microwave Limb Sounder stratospheric ozone measurements, J. geophys. Res., 113, D15S20, doi:10.1029/2007JD008771, 2008.

Joiner J. and Bhartia, P. K.: The Determination of Cloud Pressures from Rotational-Raman Scattering in Satellite Backscatter U1traviolet Measurements, J. Geophys. Res., 100, 23019-23026, 1995.

Joiner, J., Vasilkov, A. P., Flittner, D. E., Gleason, J. F., and Bhartia, P. K.: Retrieval of cloud pressure and oceanic chlorophyll content using Raman scattering in GOME ultraviolet spectra, J. Geophys. Res., 109, D01109, doi:10.1029/2003JD003698, 2004.
Joiner, J. and Vasilkov, A. P.: First results from the OMI Rotational Raman Scattering Cloud Pressure Algorithm, IEEE T. Geosci. Remote, 44, 1272-1282, 2006.

Joiner, J., Vasilkov, A. P., Yang, K., and Bhartia, P. K.: Observations over hurricanes from the ozone monitoring instrument, Geophys. Res. Lett., 33, L06807, doi:10.1029/2005GL025592, 2006.

Kley, D., Crutzen, P. J., Smit, H. G. J., et al.: Observations of nearzero ozone concentrations over the convective Pacific: Effects on air chemistry, Science, 274, 230-233, 1996.

Kroon, M., Petropavlovskikh, I., Shetter, R. E., Hall, S., Ullmann, K., Veefkind, J. P., McPeters, R. D., Browell, E. V., and Levelt, P.: OMI Total Ozone Column Validation with AuraAVE CAFS Observations, J. Geophys. Res., 113(D15), D15S13, doi:10.1029/2007JD008795, 2008a.

Kroon, M., Veefkind, J. P., Sneep, M., McPeters, R. D., Bhartia, P. K., and Levelt, P.: Comparing OMI-TOMS and OMI-DOAS total ozone column data, J. Geophys. Res., 113(D16), D16S28, doi:10.1029/2007JD008798, 2008b.

Levelt, P. F., Van den Oord, G. H. J., Dobber, M. R., et al.: The Ozone Monitoring Instrument, IEEE Trans. Geosci. Remote Sens., 44(5), 1093-1101, 2006.

Liu, H. Y., Crawford, J. H., Pierce, R. B., et al.: Radiative effect of clouds on tropospheric chemistry in a global three-dimensional chemical transport model, J. Geophys. Res., 111(D20), D20303, doi:10.1029/2005JD006403, 2006.

Logan, J. A., Megretskaia, I., Nassar, R., et al.: Effects of the 2006 El Nino on tropospheric composition as revealed by data from the Tropospheric Emission Spectrometer (TES), Geophys. Res. Lett., 35, L03816, doi:10.1029/2007GL031698, 2008.

McPeters, R. D., Kroon, M., Labow, G. J., Brinksma, E., Balis, D., Petropavlovskikh, I., Veefkind, J. P., Bhartia, P. K., and Levelt, P.: Validation of the Aura Ozone Monitoring Instrument Total Column Ozone Product, J. Geophys. Res., 113(D15), D15S14, doi:10.1029/2007JD008802, 2008.

Menzel, W. P., Wylie, D. P., and Strabala, K. I.: Seasonal and diurnal changes in cirrus clouds as seen in four years of observations with the VAS, J. Appl. Meteorol., 31, 370-385, 1992.

Platnick, S., King, M. D., Ackerman, S. A., Menzel, W. P., Baum, B. A., Riédi, J. C., and Frey, R. A.: The MODIS cloud products: algorithms and examples from Terra, IEEE T. Geosci. Remote, 41, 459-473, 2003.

Rozanov, V. V., Kokhanovsky, A. A., and Burrows, J. P.: The determination of cloud altitudes using GOME reflectance spectra: Multilayered cloud systems, IEEE T. Geosci. Remote, 42, 10091017, 2004.

Schoeberl, M. R., Ziemke, J. R., Bojkov, B., et al.: "A trajectory-based estimate of the tropospheric ozone column using the residual method", J. Geophys. Res., 112, D24S49, doi:10.1029/2007JD008773, 2007.

Solomon, S., Thompson, D. W. J., Portmann, R. W., et al.: On the distribution of and variability of ozone in the tropical upper troposphere: Implications for tropical deep convection and chemical-dynamical coupling, Geophys. Res. Lett., 32, L23813, doi:10.1029/2005GL024323, 2005.

Sneep, M., De Haan, J., Stammes, P., Wang, P., Vanbauce, C., Joiner, J., Vasilkov, A., and Levelt, P.: Three way comparison between OMI/Aura and POLDER/PARASOL cloud pressure products, J. Geophys. Res., 113(D15), D15S23, doi:10.1029/2007JD008694, 2008. 
Spurr, R., de Haan, J. F., van Oss, R., and Vasilkov, A.: Discrete ordinate radiative transfer in a stratified medium with first order rotational Raman scattering, J. Quant. Spectrosc. Ra., 109, 404425, 2007.

Stephens, G. L., Vane, D. G., Boain, R. J., et al.: The CloudSat Mission and the A-Train: A new dimension of space-based observations of clouds and precipitation, B. Am. Meteorol. Soc., 83, 1771-1790, 2002.

Thompson, A. M., Witte, J. C., McPeters, R. D., et al.: Southern Hemisphere Additional Ozonesondes (SHADOZ) 1998-2000 tropical ozone climatology - 1. Comparison with Total Ozone Mapping Spectrometer (TOMS) and groundbased measurements, J. Geophys. Res., 108(D2), 8238, doi:10.1029/2001JD000967, 2003.

van Roozendael, M., Loyola, D., Spurr, R., et al.: Ten years of GOME/ERS-2 total ozone data, The new GOME data processor (GDP) version 4: 1. Algorithm description, J. Geophys. Res., 111, D14311, doi:10.1029/2005JD006375, 2006.

Vasilkov, A., Joiner, J., Spurr, R., et al.: Evaluation of the OMI cloud pressures derived from rotational Raman scattering by comparisons with other satellite data and radiative transfer simulations, J. Geophys. Res., 113, D15S19, doi:10.1029/2007JD008689, 2008.
Zhu, B., Xiao, H., Huang, M., and Li, Z.: Numerical study of cloud effects on tropospheric ozone, Water Air Soil Poll., 129, 199216, 2001.

Ziemke, J. R., Chandra, S., and Bhartia, P. K.: Two new methods for deriving tropospheric column ozone from TOMS measurements: The assimilated UARS MLS/HALOE and convective cloud differential techniques, J. Geophys. Res., 103, 22115-22127, 1998.

Ziemke, J. R., Chandra, S., and Bhartia, P. K.: "Cloud slicing": A new technique to derive upper tropospheric ozone from satellite measurements, J. Geophys. Res., 106, 9853-9867, 2001.

Ziemke, J. R., Chandra, S., and Bhartia, P. K.: Upper tropospheric ozone derived from the Cloud Slicing technique: Implications for large-scale convection, J. Geophys. Res., 108(D13), 4390, doi:10.1029/2002JD002919, 2003.

Ziemke, J. R., Chandra, S., Duncan, B. N., et al.: Tropospheric ozone determined from Aura OMI and MLS: Evaluation of measurements and comparison with the Global Modeling Initiative's Chemical Transport Model, J. Geophys. Res., 111, D19303, doi:10.1029/2006JD007089, 2006. 